\title{
A CAPACITAÇÃO DOS PROFESSORES TUTORES NO PROGRAMA PEC-FORMAÇÃO UNIVERSITÁRIA ATRAVÉS DOS DESAFIOS DA PRÁTICA
}

\author{
Maria Ângela Barbato Carneiro ${ }^{1}$ \\ Hilda Lúcia Cerminaro Sarti ${ }^{2}$
}

Resumo: O objetivo deste trabalho foi identificar, entre os professores tutores do PEC- Formação Universitária, os desafios encontrados na prática e detectar os desafios por ele provocados.Para alcançar este objetivo se utilizou uma metodologia qualitativa baseada no registro de depoimentos e entrevistas.

O trabalho desenvolveu-se em três etapas. A primeira consistiu no registro da declaração dos sujeitos obtidos durante as três primeiras reuniões mensais do projeto. A segunda teve a coordenação atuando como apoio através de reuniões ocorridas nos diversos locais de trabalho. A terceira etapa se concretizou por meio de entrevistas semi-estruturadas, buscando identificar quais os problemas ainda se mantinham, as soluções encontradas e os avanços conseguidos.

Verificou-se, no final, que os sujeitos haviam aprendido a utilizar novos espaços de aprendizagem além de terem se preparado melhor através do aprofundamento de estudos e do trabalho em grupo.

Palavras chaves: formação, professores tutores, desafios e mudanças

\footnotetext{
${ }^{1}$ Faculdade de Educação Pontifícia Universidade Católica de São Paulo

${ }^{2}$ Doutoranda do Programa de Educação e Currículo Pontifícia Universidade Católica de São Paulo
} 


\section{Introdução}

A partir da década de 70 os países de todo o mundo têm passado por uma série de mudanças.Especialmente nas duas últimas décadas, com o desenvolvimento do setor quaternário, a matéria-prima passou a ser a informação que transformou a economia local em economia mundial. Isso exigiu por um lado, uma educação de melhor qualidade, por outro, um homem mais reflexivo, criativo e conhecedor de um saber plural.

Esta nova sociedade, denominada de sociedade do conhecimento, é, na realidade, uma sociedade de aprendizagem, pois a economia deixou de funcionar não só a partir da força das máquinas mas também passou a ser impulsionada pelo cérebro, ou seja, pelo poder de pensar, de criar, de inovar, de aprender. Assim sendo, a universalidade cedeu lugar à singularidade, à unidade, à complexidade e, também, ao consenso e à diversidade.

O mundo está cada vez mais complexo, interdependente e vem se transformando em um ritmo alucinante, com uma urgência maior no processo de resolução de problemas, necessitando de respostas mais imediatas e eficazes.Nesse novo contexto, como muito bem mostrou Hargreaves (2004), do ponto de vista político, uma educação de qualidade é essencial para o desenvolvimento de trabalhadores do conhecimento e das sociedades em todas as partes do mundo.

No entanto, a resposta não está na educação que ainda vivenciamos, na maioria das vezes, tradicional, baseada exclusivamente no ato de ensinar, mas fincada essencialmente nas condições de aprendizagem.

O ensino deve, portanto, enfatizar cada vez mais algumas habilidades tais como raciocínio, reflexão, estratégias de cooperação, desenvolvimento de inteligências múltiplas, entre outras.

Como formar os professores para a sociedade atual se os que temos aprenderam observando seus mestres? Como prepará-los diante de um conhecimento que se torna cada vez mais complexo?

Hoje os professores precisam ser mais comprometidos e engajados com seu contexto, aprimorar seus conhecimentos através da aprendizagem contínua, de 
modo que se transformem em elementos ativos, participantes e criativos do processo educativo.

Tal necessidade parece ser indispensável, principalmente quando se trata do processo de formação docente, especialmente em um momento em que as novas tecnologias da comunicação e da informação ganham espaço na escola.

Nesse sentido, este trabalho se insere na perspectiva de aprofundar o estudo sobre as condições do trabalho dos professores tutores, no programa PECFormação Universitária desenvolvido pela Pontifícia Universidade Católica de São Paulo durante 2001 e 2002 em parceria com a Secretaria Estadual de Educação de São Paulo, além de outras duas universidades públicas (USP e UNESP) e das mudanças propiciadas pelo referido programa no seu processo de formação.

\section{Justificativa}

Os avanços tecnológicos, as atuais concepções de trabalho e de produção configuram o que se denomina sociedade da informação e do conhecimento, apontando para uma nova ordem mundial, ressaltando concepções de saber articuladas à questão do poder entre as mais diversas culturas, povos e nações.

O grande desafio que se impõe hoje para a universidade e para a educação geral situa-se na compreensão da profunda revolução do universo do conhecimento que, potencializado pela explosão tecnológica, tem alterado de forma significativa o contexto das situações de trabalho e de vida das pessoas.

Este novo cenário, marcado pelas perplexidades que a utilização de novas tecnologias de informação trazem para a construção do conhecimento, alteram definitivamente o processo de formação de professores apontando para a necessidade de uma nova forma de cultura que, dentre os vários atributos, revela a importância do desenvolvimento pessoal e profissional mesclados pela autonomia e auto formação dos sujeitos envolvidos.

Neste sentido, a formação docente entendida como uma dimensão de reconstrução permanente da identidade pessoal e profissional não pode ser vista mais como um processo de acumulação de conhecimentos dispostos de forma estática (cursos, teorias, livros, técnica), desvinculados da concepção e da análise dos 
contextos sociais que produzem um conjunto de valores, saberes e atitudes, os quais imprimem significados ao fazer educativo. Tal visão torna-se inadequada dada, por um lado, a relatividade do conhecimento e, por outro, a necessidade de novas aprendizagens e novos saberes que possam fazer com que a educação contribua para melhorar as condições de vida entre os homens.

Com essa perspectiva não é apenas o aluno que aprende mas, também, o professor uma vez que tanto os seus saberes quanto seus fazeres necessitam ser revistos continuamente. Isso ocorre porque "as aprendizagens devem evoluir e não podem mais ser consideradas como simples transmissão de práticas mais ou menos rotineiras... “(Delors, 1996: 80)

A educação tornou-se, pois, um fator indispensável para o desenvolvimento e poderá permitir um melhor equilíbrio das relações econômicas. Assim, torna-se fundamental a valorização de novos paradigmas de formação que desencadeiem nos professores/ formadores um processo de aprendizagem e reflexão contínuas buscando não só relacionar a teoria e a prática, mas a solucionar problemas, a cooperar, a tomar decisões, a formular seus próprios juízos de valor.

\section{Objetivo}

O programa PEC- Formação Universitária foi um projeto realizado pela Secretaria Estadual de Educação do Estado de São Paulo, que ao perceber a dicotomia entre o saber e o fazer pedagógico dos docentes da rede pública estadual de ensino, teve como diretriz fugir dos modelos tradicionais presentes nos cursos de formação docente envolvendo ações que pudessem promover a articulação permanente entre a teoria e a prática, valorizasse o exercício da docência e criasse um ambiente educativo. Por essa razão se estruturou em módulos tratados na forma de eixos temáticos, adotou novas metodologias e contratou vários profissionais (teleconferencistas, vídeo-conferencistas, professores tutores, professores assistentes e professores orientadores), buscando trabalhar com diferentes espaços de aprendizagem que pudessem, de alguma forma, melhorar a qualidade dos saberes/ fazeres do professor da rede pública na sala de aula. 
A presente investigação portanto, teve como objetivo identificar entre os professores tutores do PEC (PUC-SP) quais os desafios encontrados na sua prática docente e quais as mudanças por eles provocadas durante a realização do projeto.

\section{Metodologia}

Uma vez que o PEC era um projeto especial e sua realização atenderia um grupo particular de docentes, havia interesse em solucionar rapidamente os problemas apresentados, de modo que os objetivos traçados, em relação à formação de professores, fossem alcançados.

Isso fez com que, do ponto de vista da pesquisa se adotasse o modelo de análise qualitativa partindo do ambiente natural, ou seja, o registro dos depoimentos dos professores tutores levantados durante as três primeiras capacitações, realizadas após o início do curso, buscando diagnosticar os obstáculos encontrados por eles na prática e auxiliá-los de modo a superação dos problemas.

Por essa razão, a pesquisa teve um processo de avaliação contínua assumindo, assim, um caráter descritivo, ou seja, os dados recolhidos foram obtidos de diversas maneiras e em inúmeras reuniões através do registro de depoimentos e entrevistas, que uma vez analisados, acabou permitindo que se acompanhasse passo a passo o desenrolar do trabalho, garantindo condições adequadas para o processo ensino aprendizagem.

Mais do que simples resultados finais o maior interesse da pesquisa consistiu em detectar, no desenrolar do projeto, os desafios encontrados na prática docente pelos professores tutores e quais as soluções encontradas para superarem os problemas, pois eles se constituíam em personagens chaves do trabalho, já que interagiam diretamente com os professores-alunos, sem a interferência de recursos midiáticos, sendo conseqüentemente capazes de identificar seus anseios, angústias, avanços e dificuldades.

Do ponto de vista metodológico, optou-se pelo procedimento de estudo de caso, pois a pesquisa deu-se dentro de um contexto específico, o programa em questão, cujas características eram distintas de outros cursos da mesma universidade e das universidades parceiras. Além disso, como se objetivava remover rapidamente os 
obstáculos detectados pelos profissionais, sujeitos da pesquisa, no desenrolar do projeto, buscando auxiliá-los na sua prática, a investigação apresentou também a dimensão de pesquisa-ação, pois se tratou " de produzir conhecimentos sobre os problemas vividos pelos profissionais, com vistas a melhorar a sua própria atuação"(Pereira,1998:154).

\subsection{Contexto: O que foi o PEC- Formação Universitária}

As mudanças econômicas, sociais e políticas pelas quais vêm passando os diversos países do planeta, têm demandado reformas educacionais urgentes que se voltam, entre outras coisas, para o processo de formação docente, pois a educação vem sendo considerada, por inúmeros estudiosos como um fator responsável pelo desenvolvimento dos países e dos diferentes povos.

O Brasil também vem sofrendo as conseqüências das transformações mundiais e dada a inadequação da legislação educacional vigente, passou por uma reforma de ensino a partir da Lei de Diretrizes e Bases da Educação Nacional 9394/96, que dentre outras coisas exigiu que a formação de docentes para a Educação Básica fosse realizada em nível superior.

Como a Secretaria da Educação do Estado de São Paulo observou que a maioria de seus professores efetivos não possuía tal formação, resolveu dar cumprimento à exigência legal, criando através da Deliberação do CEE 12/2001 alterada pela Deliberação CEE 13/2001 um programa especial que levasse em conta a experiência do trabalho buscando articular a teoria e a prática, que valorizasse o exercício da docência e criasse um ambiente que fizesse uso das mídias interativas no desenvolvimento das competências profissionais, de modo a atender os princípios que orientam a educação básica em curso no país.

Embora tais documentos tivessem sido aprovados durante o mês de abril de 2001, o início do programa só ocorreu a partir de julho do mesmo ano.

Nesse trabalho a Secretaria Estadual de Educação de São Paulo estabeleceu parceria com três universidades (Universidade de São Paulo-USP, Universidade Estadual Paulista -UNESP e Pontifícia Universidade Católica de São Paulo -PUC/SP) todas bastante conceituadas pelos trabalhos realizados. 
Coube à Secretaria a elaboração do Projeto Básico do Curso, contendo as diretrizes gerais e a adoção das providências necessárias para o seu desenvolvimento. Já as três universidades foram responsáveis pelo detalhamento pedagógico e metodológico do programa, de modo a promover a contínua articulação entre a teoria e a prática, pela criação de um ambiente educativo, pela definição e constituição das equipes de trabalho, pelos materiais de apoio, pelas ações docentes e certificação dos professores.

Esse programa foi semi-presencial, com duração de apenas 18 meses, porém cumprindo as exigências legais de garantir uma carga horária de 3100 horas, sendo estruturado sob a forma modular, integrando os conteúdos de maneira interdisciplinar e usando novas tecnologias da comunicação e da informação no processo ensino-aprendizagem.

Nele valorizou-se a articulação entre os saberes da experiência pessoal e os de natureza teórica científica fazendo com que a proposta estivesse fundamentada sobre três eixos básicos:

_ a valorização da experiência docente como forma de conhecimento;

_ a articulação entre os saberes da experiência com os de teoria adquirida; e

_ a aprendizagem midiatizada por recursos de moderna tecnologia.

Do ponto de vista metodológico, a dinâmica de funcionamento do programa previa cinco modalidades de atividades que, articuladas entre si, davam consistência à proposta pedagógica. Eram elas:

_ as teleconferências ministradas por convidados das Universidades, Instituições de Ensino Superior ou pela Secretaria Estadual de Educação;

_ as videoconferências, ministradas por docentes mestres e doutores indicados pelas universidades;

_ o trabalho monitorado abrangendo sessões on line, off line e sessões de suporte, supervisionadas por tutores ou assistentes indicados pelas universidades;

_ as vivências educadoras, isto é, atividades complementares realizadas sob a supervisão dos tutores e/ou orientadores; e, 
_os estudos independentes e trabalhos de síntese elaborada do programa, sob a supervisão dos orientadores acadêmicos indicados pelas universidades.

\subsection{Quem eram os profissionais que atuavam no PEC?}

Dada a complexidade do PEC- Formação Universitária e ao uso de diferentes espaços de aprendizagem optou-se por um programa semi-presencial, organizado em módulos, com o apoio de mídias interativas (teleconferências, videoconferências, trabalhos on e off-line).

Para a sua realização, o programa contou com vários profissionais (teleconferencistas, videoconferencistas, professores tutores, professores assistentes e professores orientadores) que atuaram nas diversas situações do processo ensino aprendizagem, dada a necessidade de atingir a uma população bastante numerosa, cerca de 7000 docentes, em todo o Estado de São Paulo.

Os teleconferencistas eram profissionais convidados pelas universidades participantes do programa ou pela Secretaria do Estado da Educação de São Paulo, cujo trabalho ocorria em tempo real e que introduziam os grandes temas a serem tratados, atingindo todos os alunos do PEC.

Os videoconferencistas eram professores de cada universidade partícipe, ou contratados por ela, para trabalhar determinados conteúdos curriculares atuando on -line com seus alunos a partir dos grandes temas introduzidos nas teleconferências.

Tanto os teleconferencistas como os videoconferêncistas ministravam suas aulas à distância, mas havia em cada sala um professor tutor, cujo trabalho de suporte era presencial e que deveria acompanhar um grupo de alunos que variava, dependendo do local, entre 18 e 45 pessoas. Era função do professor tutor, no início do projeto, motivar e interessar os alunos para participarem das tele e das videoconferências bem como auxiliá-los nas suas necessidades mais imediatas. Foi sobre este profissional que incidiu a nossa investigação e que trataremos mais adiante.

Além dos profissionais já citados havia também professores assistentes, alunos de cursos de mestrado e doutorado das universidades participantes, que trabalhavam off-line com os professores-alunos dissipando as dúvidas dos assuntos tratados. 
Como o PEC estabelecia, entre outras coisas, que ao término do curso os alunos deveriam elaborar um trabalho de conclusão (TCC), buscando de alguma forma melhorar a prática de sala de aula, foram contratados pela universidade docentes, ou seja, professores orientadores, possuidores de títulos de mestres ou doutores para o desempenho dessa função. A tarefa era presencial e os encontros, a princípio mensais, mas que com o tempo acabaram passando a quinzenais e, por vezes, até semanais.

\subsection{Os professores tutores}

Como vimos anteriormente, os professores tutores tinham um trabalho presencial com um grupo de alunos, buscando, por um lado estimulá-los a participar das tele e das videoconferências e, por outro, dirimir as dúvidas que por ventura pudessem ocorrer no âmbito da sua competência.

A PUC-SP coordenou o trabalho de 44 grupos de alunos, estando cada um deles sob a responsabilidade de um professor tutor.Prevendo-se eventualmente a ausência de algum deles e a necessidade de substituição foram contratados 45 profissionais para desempenhar a função, 44 dos quais com postos fixos de trabalho e um volante para substituição.

Do ponto de vista do perfil exigido os tutores eram docentes que deveriam possuir Curso de Graduação na área da Educação ou áreas afins, experiência na rede pública de ensino, especialmente, nas séries iniciais do ensino fundamental, ter conhecimento dos Parâmetros Curriculares Nacionais (PCNs), ter experiência com formação de educadores, ter indicado conhecimentos de usuário e/ou domínio dos aplicativos de informática,

Todos os tutores da PUC-SP foram selecionados a partir de um perfil traçado, da experiência de trabalho na rede pública além de se levar em consideração a disponibilidade de horário e de acesso à localidade ${ }^{3}$ onde seria ministrado o curso.

\footnotetext{
${ }^{3}$ Eram seis as localidades, também denominadas de pólos, onde o curso ocorria. Havia um pólo na cidade de Sorocaba e, os demais, nos bairros de Pirituba, Interlagos, Tucuruvi, Itaquera e Artur Alvim na cidade de São Paulo.
} 
Além dos quesitos descritos, os candidatos também se submeteram a uma entrevista com a coordenação pois por ela deveriam ser supervisionados durante todo o período em que durasse o projeto.

$\mathrm{Na}$ entrevista, a coordenação pedagógica do PEC da PUC/SP definiu alguns critérios complementares para a seleção dos professores tutores, tais como, ter uma sólida formação teórica que pudesse favorecer o trabalho nas diferentes áreas do saber, além de conhecimentos de aspectos legais e políticos da educação. Esse trabalho não só foi árduo como, também, complexo.

Inicialmente traçou-se um perfil do professor tutor como um profissional que pudesse acompanhar todas as atividades presenciais do aluno, assistir às tele e às videoconferências, estimular as discussões em sala de aula bem como a realização dos exercícios complementares após as videoconferências, supervisionar os trabalhos monitorados, avaliar as tarefas dos alunos, controlar a freqüência e elaborar e encaminhar os relatórios para a coordenação.

"O projeto, por estar em construção, na prática apresentou desdobramentos não imaginados no início..." (Sarti, 2005:68)

Os professores tutores escolhidos receberam uma capacitação inicial com a duração de uma semana em período integral, ocasião em que foram esclarecidas as dúvidas em relação a questões contratuais, ao papel profissional e fornecidas informações sobre alguns conteúdos iniciais que seriam trabalhados nas três primeiras semanas de curso. Tiveram, ainda, um treinamento especial para o uso do equipamento de videoconferência e do learnig space, além do recebimento de manuais contendo instruções básicas para a utilização das tecnologias..

Desde o princípio era objetivo da coordenação acompanhar a atuação dos tutores, não só por se tratar de um projeto inédito, como também porque dada a utilização das tecnologias da informação e da comunicação, dificuldades poderiam se apresentar , interferindo na aprendizagem do aluno.

No entanto, o que não se esperava é que a rede telemática, do ponto de vista técnico, apresentasse tantos problemas, especialmente no três primeiros meses de curso quando a maioria das videoconferências não ocorria em todos os lugares, o 
que fez com que os professores tutores tivessem inúmeras dificuldades, dentre elas, a de assumir o papel dos videoconferencistas.

\section{A pesquisa}

Participaram da pesquisa 45 sujeitos ( professores tutores) dos quais, inicialmente eram 40 mulheres e 5 homens e, posteriormente, com a saída de um tutor e a entrada de outro, permaneceram 41 mulheres e 4 homens. Todos eles foram selecionados pela Pontifícia Universidade Católica para atuarem nos pólos do Programa PEC- Formação Universitária sob sua responsabilidade.

Foi um projeto único e singular estruturado sobre o tripé planejar, fazer e rever, num processo dialético.

Como o objetivo da pesquisa consistia, em um primeiro momento, em diagnosticar as situações-problema vivenciadas por parte dos professores tutores, que pudessem interferir na sua prática.

Em um segundo momento, nos interessava saber quais as soluções que eles haviam encontrado para superar os obstáculos sentidos e em um terceiro momento, buscávamos investigar as transformações ocorridas, por aqueles profissionais,

A pesquisa contou, portanto, com três etapas de trabalho.A primeira consistiu no registro dos depoimentos dos sujeitos a partir das gravações das três primeiras reuniões mensais, organizadas pela coordenação, buscando levantar quais eram as dificuldades sentidas.

É importante ressaltar que, na ocasião, era objetivo tanto da Universidade quanto da Secretaria da Educação do Estado de São Paulo, detectar as situaçõesproblema enfrentadas pelos professores tutores, pois uma vez que este curso não se repetiria, as falhas deveriam ser sanadas rapidamente. Ao mesmo tempo, dado o uso de tecnologias interativas a coordenação tinha como finalidade avaliar quais as transformações que o curso produziria nos referidos professores, até mesmo porque alguns deles havia algum tempo que haviam passado pelo processo de formação e todos eles apresentavam pouca familiaridade no uso das tecnologias da comunicação e da informação. 
Uma vez detectados os obstáculos na atuação dos tutores durante os três encontros iniciais promovidos pela coordenação a segunda etapa constou, por parte dessa última, em oferecer suporte aos docentes investigados. Tal aporte ocorreu através da alteração na sistemática das reuniões, na maneira de prover as videoconferências não transmitidas e no oferecimento de diversos subsídios que pudessem auxiliá-los na tarefa cotidiana.Além disso, começava-se a perceber uma alteração do papel do tutor, em relação ao que havia sido projetado no início do trabalho.

Apesar de os encontros mensais continuarem a existir, as situaçõesproblema originaram outros, quinzenais e até semanais, de acordo com a demanda, realizando-se, em geral, no próprio local de trabalho dos tutores.Tais reuniões objetivavam solucionar ou pelo menos minimizar rapidamente os problemas diagnosticados de modo a impedir qualquer tipo de prejuízo ao aluno professor na busca de um trabalho verdadeiramente democrático. Muitos dos obstáculos também decorriam do pouco tempo existente entre o planejamento dos módulos e sua execução, exigindo por parte de todos rapidez na tomada de decisão.

Detectados os problemas e encontradas as soluções para alguns deles entramos na terceira etapa da pesquisa.

Realizada pela coordenação ao fim do primeiro ano de trabalho, a terceira etapa constou de uma entrevista semi-estruturada com os sujeitos, buscando saber que problemas persistiam, quais os que haviam sido solucionados e de que forma isso ocorrera e quais as transformações que os tutores haviam sentido.

As entrevistas foram individuais, realizadas no espaço da coordenação, na universidade e tiveram cerca de uma hora de duração.

\section{Os resultados}

Durante as três primeiras capacitações que se sucederam ao encontro inicial, faltaram apenas dois sujeitos, pois estavam pedindo demissão. Foram gravados os depoimentos dos professores tutores colocando suas principais dificuldades.

$\mathrm{Na}$ ocasião os tutores deixaram claro que haviam se identificado muito bem com os objetivos do curso, tais como a reflexão sobre a prática e a possibilidade 
de articulá-la com as diversas teorias, o resgate da auto-estima do docente da rede pública estadual, a melhoria da qualidade do ensino e a transformação da prática pedagógica.Existiam, porém, inúmeros problemas.

Houve unanimidade por parte dos sujeitos em colocar que o maior obstáculo referia-se aos problemas técnicos (falta de imagem ou de som ou dificuldade na transmissão), o que, muitas vezes, acabava impedindo a realização das videoconferências.

Tal problema gerava um grande desconforto por parte dos tutores, pois não estavam preparados para assumirem emergencialmente a posição dos videoconferencistas, até mesmo porque não eram especialistas nos assuntos tratados. Além disso, a representação que tinham do seu papel era apenas de colaboradores no sentido de motivar os alunos para o trabalho.

Alguns dos depoimentos demonstraram tal descontentamento:

Sujeito 1 "É impossível trabalhar dessa forma todos os dias temos problemas técnicos e não se realiza a videoconferência".

Sujeito 3 "Estou extremamente angustiada, pois não sou especialista no assunto e se o material não chega com antecedência não tenho como me preparar para realizar o trabalho".

Sujeito 6 "Não fomos preparados para dar as aulas, não somos especialistas".

Sujeito 13 “ A Secretaria de Educação e a Telefônica deveriam ter se preparado melhor do ponto de vista técnico, antes de iniciar o curso”.

Sujeito 24 "A nossa função não é a de substituir o videoconferencista..."

Sujeito 28 "A capacitação que tivemos inicialmente não deu conta do conteúdo e como tudo acontece muito rápido não dá tempo de realizarmos um aprofundamento adequado do assunto a ser tratado”.

Sujeito 40 "Não estava previsto que teríamos que ministrar aula integral para os alunos-professores. Algumas vezes, tive que fazê-lo, por problemas técnicos na videoconferência. Outras vezes, devido à complexidade do tema para o aluno não familiarizado com ele, precisei praticamente reapresentar a aula". 
Trinta e cinco deles colocaram o atraso no envio dos materiais de apoio por parte da Secretaria Estadual de Educação de São Paulo, bem como a dificuldade em conseguí-los com antecedência junto à direção da unidade escolar, onde era ministrado o PEC. Alguns depoimentos ilustram melhor tal realidade.

Sujeito 10 "O material está chegando em cima da hora, não dá tempo de preparar o assunto".

Sujeito 25 "O diretor da unidade tranca tudo e, se ele não está, o material não pode ser entregue”.

Sujeito 34 "Se o material chegasse pelo menos com uma semana de antecedência teríamos tempo de lê-lo melhor e prepararmos melhor o trabalho”.

Sujeito 41 "O curso foi planejado para ser dado por especialistas e eu não sou especialista em diferentes assuntos".

É importante salientar que os diretores das unidades, não tinham nenhuma relação com o projeto, apenas o abrigavam em sua instituição, não estabelecendo, com ele, nenhum tipo de vínculo. Isso, por vezes, dificultou muito o trabalho.Sobretudo em relação a distribuição do material didático, foram inúmeros os problemas criados, como por exemplo, a falta de comunicação por ocasião do recebimento do referido material da secretaria da Educação, a dificuldade em ter um encarregado na escola para entregá-lo ao tutor e inúmeras outras situações que acabaram resultando em conflitos.

Outra questão levantada por todos eram as contínuas alterações nos cronogramas. O curso teve 55 cronogramas e isso, certamente, atrapalhava o trabalho.

Sujeito 2 "O cronograma se altera praticamente toda semana o que dificulta qualquer planejamento".

Sujeito 10 "È muito difícil trabalhar com um cronograma que está sempre em mudança”.

Sujeito 21 "A flexibilidade do cronograma impede uma preparação maior no trabalho".

Vinte e oito expressaram o pouco tempo existente para o desenvolvimento dos temas e textos em função da sua complexidade. 
Sujeito 3 “ Acaba ficando muito corrido o trabalho porque as atividades propostas em cada tema são muitas e complexas".

Sujeito 19 "As atividades propostas são muitas e complexas..."

Sujeito 40" Se poderia pensar em diminuir o número das atividades para que os alunos tivessem tempo de realizá-las adequadamente”.

Quatorze tutores solicitaram um aporte da coordenação, no sentido de superar os obstáculos encontrados e auxiliar a solucionar as dúvidas sobre o conteúdo do material que pudessem surgir, até mesmo porque precisavam de um tempo maior para ler.

Sujeito 11" As capacitações são muito distantes, deveríamos ter reuniões semanais".

Sujeito 26 "Tenho muitas dúvidas e, nem sempre, consigo solucioná-las com os meus colegas".

Sujeito 31 "Tudo é muito rápido, não dá tempo de discutir direito, precisamos de uma melhor formação, uma vez que temos que substituir os videoconferencistas".

Dez profissionais apresentavam problemas de relacionamento com o grupo.

Sujeito 7 “ O grupo é muito difícil”.

Sujeito 16 "Há uma liderança negativa que se coloca frontalmente contra tudo, até mesmo as normas regimentais do curso”.

Sujeito 32 "Há professores-alunos que não querem nada com nada”.

Sujeito 43 "O grupo é um grande desafio".

Surgiram outros problemas, como por exemplo, a questão da curta duração do curso, a falta de plantonista (estagiário) para dar suporte no trabalho com os equipamentos, a deficiência de leitura dos alunos-professores, a falta de interesse no acompanhamento do curso, o cansaço, o grande período que haviam passado sem capacitação, além da inadequação do espaço físico das classes para o grande número de alunos. Tais problemas podem ser mais explicitados através do depoimento de um dos sujeitos: 
Sujeito 35 “Afastados há muito tempo dos bancos escolares, sem nenhum preparo, ao alunos têm encontrado muitas dificuldades que tentamos minimizar com o nosso trabalho. É um contínuo movimento de apagar incêndios.”

A partir dos problemas diagnosticados nos três primeiros encontros observou-se que as reuniões da coordenação eram insuficientes diante do gigantismo do projeto e da multiplicidade de problemas encontrados, o que obrigou a sua realização em períodos mais curtos de tempo utilizando não só a relação direta, mas as comunicações digitais que ocorriam diariamente, estabelecendo contínuas relações de troca e cooperação na busca de soluções viáveis que pudessem atender a demanda.

Nessas reuniões, oferecia-se ao tutor material complementar, sugestões bibliográficas e de procedimentos, discutiam-se problemas e buscava-se, em conjuntos, soluções para os obstáculos enfrentados.

Muitas orientações também foram feitas através de outros meios de comunicação tais como, telefone, fax, e-mail e mensageiro.

No entanto, nem sempre tais recursos eram adequados, principalmente, quando aos problemas técnicos adicionava-se o de relacionamento da equipe. Além disso, os obstáculos de ordem técnica persistiram por muito tempo. Isso fez com que o tempo para o desenvolvimento de alguns temas e textos fosse insuficiente.

Foi assim que decorrido um ano do programa, foram realizadas entrevistas semi-estruturadas com os tutores. Na ocasião evidenciavam-se três aspectos, quais as dificuldades ainda presentes no cotidiano, que soluções haviam encontrado para superá-las e quais os avanços que julgavam significativos em relação à sua formação.

Embora os problemas técnicos, os relativos ao cronograma e o pouco tempo para desenvolver as atividades propostas no material, ainda se apresentassem foi possível perceber que as medidas adotadas pela coordenação permitiram que os profissionais se sentissem mais seguros e preparados. Em seus depoimentos, elogiavam a gestão democrática e participativa utilizada pela equipe de coordenação PUC-SP, pois favoreciam a resolução dos problemas e a socialização de sugestões.

"Pensar e agir na complexidade oportunizou o desenvolvimento de relações de confiança e cooperação entre parceiros, com sensibilidade para respeitar 
seus limites e também para considerar as características de cada um, sua história pessoal e profissional “. (Sarti, 2005:74)

Sujeito 5" A coordenação tem nos ajudado muito, procurando atender rapidamente as nossas necessidades".

Sujeito 11" Se a coordenação não fosse rápida para solucionar os problemas teria sido mais difícil o trabalho.

Outro fator unanimemente apontado pelos tutores como responsável pela melhoria do trabalho foi a maior rapidez no envio de material complementar que incentivava-os a pesquisar e aprofundar mais o assunto. Isso favoreceu uma série de trocas e parcerias entre os tutores da mesma unidade e de unidades diferentes, tais como grupos de estudo, debates e trocas de informações. Alguns depoimentos obtidos durante as entrevistas podem esclarecer melhor a realidade.

Sujeito 15 “Tivemos que nos reunir continuamente quando chegavam os materiais para estudarmos e tirarmos as dúvidas"

Sujeito 23 "Houve um esforço conjunto de todos, na unidade, para superarmos as dificuldades no trabalho com os conteúdos”.

Sujeito 31 "Não foi fácil superar os problemas técnicos durante a videoconferência,especialmente, a falta de interação porém, o trabalho conjunto ajudou muito".

Quarenta tutores apontaram que tiveram necessidade de mais leituras e de contínua atualização para a melhoria da atuação, reforçando a relevância de um processo permanente de aprendizagem.

Salientavam que, cada vez mais, os conhecimentos mostram-se relativos, dadas as rápidas mudanças do mundo atual o que os levava “ a aprender a aprender”.

Sujeito 17 “ Esse trabalho mostrou que temos que estudar cada vez mais”.

Sujeito 37 " Nunca tive que estudar tanto na minha vida".

Sujeito 44" Tivemos que nos aprofundar em assuntos que, antes, desconhecíamos".

Uma das características principais do PEC foi o diálogo contínuo entre a teoria e a prática. A realidade vivida e observada pelos professores- alunos era 
continuamente discutida e analisada, à luz da teoria, de modo que ambas caminhassem juntas, buscando um ensino de melhor qualidade na rede pública estadual de São Paulo.

Isso ficou explícito nos depoimentos de quarenta tutores.

Sujeito 6 "O curso está muito pautado sobre a realidade e isso nos faz. refletir sobre nossas práticas".

Sujeito 36"No PEC a teoria está assentada na prática..."

Trinta e oito profissionais expressaram que tiveram que rever suas posturas e metodologias e que o uso das mídias digitais acabou fazendo parte do repertório dos procedimentos por eles utilizados.

Sujeito 2 "Tive que estudar muito e mudar a minha forma de trabalho, adotei novas metodologias”.

Sujeito 27 “ Se não fosse o PEC continuaria a trabalhar de uma forma tão arcaica, além do que tive os horizontes abertos para novos conhecimentos".

A pesquisa mostrou, que dado o cronograma extremamente flexível ${ }^{4}$ e enxuto, dificultando os encontros presenciais entre os professores tutores e a coordenação, o uso do equipamento de videoconferência além de propiciar as relações entre os tutores, também auxiliaram numa relação mais direta com a coordenação, fazendo com que tais profissionais aprendessem a utilizar novos espaços de aprendizagem, habituados durante o seu processo de formação.

Nesse sentido, ficou claro que a escola não pode ignorar o que se passa no mundo. Logo, um curso que utilizava as novas tecnologias não poderia desprezá-las no preparo de seus próprios profissionais.

Sujeito 14 "Pensei que não conseguiria ir até o fim do curso, pois tinha uma grande resistência em relação à informática”.

Sujeito 31 "Acabei me familiarizando com a tecnologia"

Os dados obtidos ressaltaram que durante as videoconferências os tutores também haviam se atualizado, pois tinham a oportunidade de refletir e debater temas mais atuais com outros profissionais.

\footnotetext{
${ }^{4}$ A flexibilidade se deve ao fato de terem ocorrido 55 cronogramas em virtude das decisões do Comitê Gestor
} 
"Os professores que sabem o que as novidades tecnológicas aportam, bem como seus perigos e limites, podem decidir, com conhecimento de causa, dar-lhes um amplo espaço em sua classe, ou utilizá-las de modo bastante marginal". (Perrenoud,2000:138)

A flexibilidade do cronograma obrigou os participantes do programa a um contínuo planejar e re-planejar de ações dados os inúmeros imprevistos, fossem eles de natureza técnica, relacional ou, ainda de caráter legal.

Isso mostra que a competência passa pela ousadia no julgamento e na tomada de decisões nos momentos de dificuldades e incertezas.

“Tomar decisões é mais do que resolver um problema, pois implica em mobilizar valores estabelecer raciocínios, enfrentar dilemas e decidir pelo que se julga melhor, mais justo, mais condizente para o sujeito e para a sociedade à qual pertence". (Macedo,2002:127)

Além disso, a realidade vivida pelos professores tutores no processo exigiu que desenvolvessem uma série de saberes, não apenas ligados aos conteúdos das videoconferências, mas aos seus fazeres, tais como, por exemplo, mediar o processo pedagógico, caracterizar e compreender as situações educativas, adequar seus saberes e seus fazeres a cada situação, tomar decisões adequadas acada momento. Daí a necessidade de aperfeiçoamento, correção, enfim, revisão. A escola, mais do que nunca, continua sendo o espaço do conhecimento, mas um saber articulado com as necessidades dos dias de hoje.

Se, a princípio, os tutores foram resistentes, dados os entraves vivenciados, com o tempo ficaram mais abertos para as mudanças, mais seguros, apresentaram maior iniciativa e criatividade na solução de problemas, aprenderam a trabalhar em equipe na unidade e, por vezes, fora dela, passaram a refletir mais sobre a importância do processo de aprendizagem do que sobre o produto final dos conteúdos ensinados. Foi um processo contínuo de ação- reflexão- ação.

$\mathrm{Na}$ maioria das unidades o trabalho dos tutores se associou ao trabalho dos professores orientadores, permitindo um avanço significativo nas concepções de ensinar e aprender. Mostraram a relevância do trabalho coletivo e do diálogo contínuo entre os diversos atores de projeto, incluindo a coordenação. 
Ressaltaram ainda as contínuas trocas de experiências propiciadas pelo programa, tanto entre os próprios tutores, quanto entre eles e seus alunos. Tudo isso mostrou que o Programa PEC- Formação Universitária (PUC-SP) teve um grande alcance social, transformou a ação docente, possibilitou a ação conjunta de diferentes agentes através dos desafios, provocou a troca de experiências, relacionou a teoria e a prática e mostrou a importância da aprendizagem significativa.

Portanto, os processos educativos, hoje, mais do que nunca, devem possibilitar aos docentes a compreensão da interdependência entre os diferentes países e as diversas culturas com economias desiguais. Desse modo a formação docente deve um caráter contínuo e permanente e não se esgotando na escola ou nos cursos de formação.

É preciso que, no mundo atual, o professor tenha um conhecimento em profundidade que possa dispô-lo, a todo momento, em função dos interesses e das necessidades do aluno. Ele deve saber enfrentar as situações problema com as quais convive cotidianamente e fazê-lo em equipe. Deve, ainda desenvolver a compreensão do outro e das interdependências e, finalmente, aprender a ser autônomo.

Para isso deve combinar o técnico, o acadêmico e o interelacional. Segundo Macedo (2002) a competência sempre envolve as relações, porque permitem ao sujeito interagir com outros sujeitos e com o mundo.Portanto, além de saber, e de saber fazer, é importante que o docente também saiba refletir e se comunicar. As situações problemas enfrentadas durante o curso foram vitais para os avanços e transformações dos professores tutores do PEC que acabaram desenvolvendo autonomia, respeito, tolerância, responsabilidade, construção de regras, amizade e compromisso.

Eles tiveram que conhecer os assuntos em profundidade porque quando as videoconferências não ocorriam, tinham que trabalhar com os alunos sob sua responsabilidade e solucionarem os problemas daquele momento, uma vez que os gestores encontravam-se espacialmente distantes das salas.

Como tais situações ocorriam continuamente, o trabalho em equipe foi a base do andamento do projeto pois as ajudas mútuas eram fundamentais para a superação dos obstáculos. 
Aprenderam a trabalhar com a diversidade dos alunos pois muitos deles havia muito tempo que estavam afastados dos bancos escolares e, portanto, tinham muita dificuldade na comunicação oral e escrita e na concentração para estudar.

Desenvolveram o senso de autonomia, planejando, executando e avaliando as ações diárias. Utilizaram tanto os recursos quanto as técnicas disponíveis, quanto criaram recursos e dinâmicas próprias a partir dos desafios encontrados. Evoluíram não só como profissionais mas, acima de tudo, como pessoas.

Vale salientar que a despeito de todas as transformações pelas quais passaram os professores tutores do PEC, ao final do projeto dez deles que se submeteram ao processo de seleção do mestrado na Universidade, apesar das exigências, todos foram aprovados.

\section{Bibliografia}

Delors, J. (2005)..A educação para o século XXI: questões e perspectivas. Porto Alegre: Artmed.

Hargreaves, A. (2004). O ensino na sociedade do conhecimento: educação na era da insegurança.Porto Alegre: Artmed.

Macedo, L. (2002). Situação -problema forma e recurso de avaliação, desenvolvimento de competências e aprendizagem escolar. In: Perrenoud, P. e outros. As competências para ensinar no século XXI: A formação dos professores e o desafio da avaliação (113-136). Porto Alegre: Artmed.

Pereira, E. M. de A. e outros (1998). Professor como pesquisador: o enfoque da pesquisa ação na prática docente. In: Geraldi, C M. G.; Fiorentini, D. e Pereira, E., M. de A. (org). Cartografias do trabalho docente (153-182). Campinas: Mercado de Letras.

Perrenoud, P. (2000). Dez novas competências para ensinar. Porto Alegre: Artmed.

Sarti, H. L. C. (2005). A trajetória do trabalho de coordenação de professores tutores do PEC-Formação Universitária: perspectivas e possibilidades. In: Feldmann, M. G. Educação e mídias interativas: Formando professores (63-86). São Paulo: EDUC. 
